\title{
Integrating Technology that Uses Modified SAMR Model as a Pedagogical Framework in Evaluating Learning Performance of Undergraduates
}

\author{
R. Sudha Nair ${ }^{1, *}$, Tay Choo Chuan ${ }^{2}$ \\ ${ }^{1}$ Centre of Liberal Arts and Languages, INTI International University, Nilai, Negeri Sembilan, Malaysia. \\ ${ }^{2}$ Faculty of Mechanical Engineering, University Technical Malaysia Melaka (UTEM), Durian Tunggal, Melaka, Malaysia.
}

\begin{abstract}
How to cite this paper: R. Sudha Nair, Tay Choo Chuan. (2021). Integrating Technology that Uses Modified SAMR Model as a Pedagogical Framework in Evaluating Learning Performance of Undergraduates. The Educational Review, USA, 5(10), 373-384.

DOI: 10.26855/er.2021.10.001
\end{abstract}

Received: August 22, 2021

Accepted: September 20, 2021

Published: October 18, 2021

Corresponding author: R. Sudha Nair, Centre of Liberal Arts and Languages, INTI International University, Nilai, Negeri Sembilan, Malaysia.

Email: rsn2001my@yahoo.com

\begin{abstract}
This is a case study on the integration of technology using a modified SAMR (Substitution, Augmentation, Modification, Redefinition) model as a pedagogical framework in teaching and learning in a private college in Melaka, Malaysia on a chosen topic in Business Communication. The study was conducted in Summer, 2019. This is a quantitative study with two groups which are control and experimental groups. The control group had gone through the traditional teaching method while the experimental group learned through technology. The model was incorporated with Bloom's Taxonomy and TPACK for credibility and reliability. All four stages of the SAMR Model were investigated for the presence of content, pedagogy, and technology. The study identified that there was the presence of content, pedagogy, and technology in the stages of augmentation, modification, and redefinition while pedagogy and content were absent in the substitution level. However, the integration of technology using the proposed pedagogical framework improved student performance in the last three stages of augmentation, modification, and redefinition with positive results. Overall, the study has evidence that the modified SAMR Model had enhanced and improved student performance. It is hoped that the outcome of this research provides valuable insight and guidance to those who want to integrate technology into the teaching and learning process.
\end{abstract}

Keywords

Technology Integration, SAMR Model, Academic Performance

\section{Introduction}

The term "technology" has gained greater prominence in the 21st century and has become an essential component in diverse fields including education. Technology is fast becoming the knowledge transfer highway in many countries, whereby its integration has gone through innovations and transformed the way people think, work and live (Grabe, 2007). In response to this, schools and other educational institutions need to consider Information and Communication Technologies (ICT) integration to prepare students to live in "a knowledge society" in their school program (Ghavifekr, Afshari, \& Amla Salleh, 2012). In order to realize this mission in Malaysia, educators need to be guided in the integration of technology in their classrooms. Technology integration when teaching students whether in classrooms or online means teachers have 'to adapt to new pedagogical concepts and modes of delivery of teaching for which they have not 
been trained' (Schlichter, 2020). The transition is not easy, and the success of the implementation depends heavily on educators having the skills, knowledge, and competencies for both methods of teaching (Winter et al., 2021). Technology is here to stay, whether we are teaching online or face-to-face. It is an important tool in the classroom and educators must know how and when to use technology appropriately (Hollebrands, 2020) in order to meet the quality and quantity of the given curriculum. This paper's objective is to use a model known as SAMR, which has been modified for the current study to integrate technology successfully. Each stage of the SAMR Model was measured by provided assessments and data computed using SPSS.

\section{Technology Integration, SAMR Model and Academic Performance}

\subsection{Technology Integration}

Technology refers to computer-based tools such as computers, multimedia, and the Internet used for teaching and learning purposes (Aloraini, 2012). Technology integration is defined as the use of computer-based communication that is incorporated in the classrooms for teaching and learning (Ghavifekr \& Rosdy, 2015). Other scholars describe technology integration in terms of types of teachers' computer use in the lecture rooms, like students doing Internet searches and multimedia presentations, collecting and interpreting data for projects (Cuban, Kirkpatrick, \& Peck, 2001).

\subsection{SAMR Model}

The Substitution, Augmentation, Modification, and Redefinition Model (SAMR) (Puentedura, 2006) is a popular framework that discusses the innovative usage of technologies for transforming learning. The SAMR model has been used as a means for educators to tackle any pedagogical changes when introducing learning technologies to students (Hogan, 2010). At the Substitution level, one is replacing an older technology in doing exactly the same activities one had done in their previous classroom. It may stage for future development however it will not form a significant impact on student outcome at this level. The second tier is augmentation where one needs to question whether we can enhance our teaching and learning with the technology that we have on hand! Rather than seeing how the students were carrying out their given task before, now we have to see the certain features in the technology that they use to accomplish the given task in a more effective, informative, and swifter manner. This will encourage improvements in students in the way they complete the given task. At the modification tier, an educator needs to accomplish the provided goals for the day's lesson. The technology will enable us to modify our teaching methods. The syllabus remains the same, but the approach used to teach the syllabus is modified so that the students can accomplish new goals which they were unable to do previously. Finally, the redefinition tier provides freedom for an educator to replace some of the old methods with newer effective ideas of teaching with the use of technology to gain students' interest.

Figure 1 shows the relationship between Bloom's taxonomy and the SAMR Model. On the first level of substitution, there are two factors which are remembering and understanding. The next level is augmentation which has understanding and application. This is followed by analyzing and evaluating on the third level. Finally, at the redefinition level, evaluation and creation follow.

The Information and Communication Technology (ICT) of the 21st century, provides new assesses and knowledge in many fields and improves the living standard of the population. By providing a new manner to engage learners in education, it is also transforming the pedagogy needs. A teacher who can bring together knowledge of a subject matter, which benefits learning and technology are known as experts when they successfully incorporate it in their classrooms. The combined three elements are described as Technological Pedagogical Content Knowledge (TPACK). Not only the TPACK encompasses technology, but pedagogy and content as well, to make it complete.

According to Dr. Puentedura (2006, 2012), to integrate technology at the Substitution level, teachers need to develop some technology knowledge in order to decide how to substitute an activity into technology based. One given example by him was substituting essay writing from paper and pen to word document. In the present study the substitution level, students will be writing an essay in a word document and submitting it through Facebook. At the augmentation level, the students are expected to be at a deep learning level of understanding. It is crucial to provide individual knowledge areas of technology, pedagogy and content however there is limited activity happening at the intersections of these bits of knowledge. The example he gave was one of building an interactive map. This is augmentation as it is something that was not possible with a paper map. In the present study, students will be communicating through Facebook to gather information on a given topic. At the modification level of SAMR changes can be observed in these intersections as the knowledge gathered becomes important. Teachers will need support at the Pedagogical Content Knowledge (PCK), Technological Content Knowledge (TCK), and Technological Pedagogical Knowledge (TPK) areas as different types of knowledge are needed to redesign tasks at this level (Kurt, 2018). Dr. Puentedura, advised of the need to develop a community of practice at schools as knowledge at the intersections of communication between teachers is most effec- 
tive and no external expert is involved. For example, taking the mapping example, he described how modern databases can be displayed on maps to visualize concepts. At this level, there are supporting exploration efforts by students. Similarly, in the current study, students are exposed to technology as each student shares information which they would have shared through Facebook. Students will prepare for the given task by accumulating data on Facebook and writing a final draft. At this level, collaboration takes place. The final stage of Redefinition of the SAMR model calls on all three knowledge areas (Content, Pedagogy, and Technology) in order to redefine the task. Once again Dr. Puentedura talked about how a community of practice is essential at the redefinition level. In addition, students need to assess the results of what they did and to communicate this to an audience outside of their class. In the present study, students will record and upload a task related to their content for public viewing.

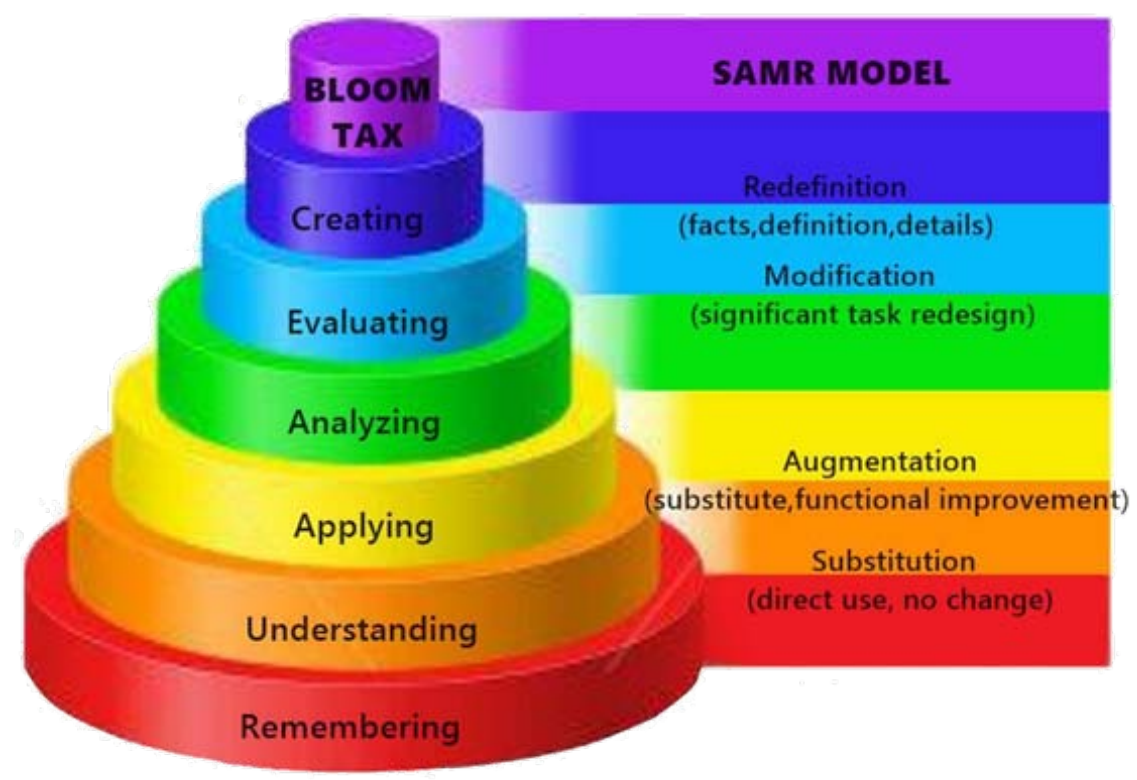

Figure 1. Relationship of Bloom's Taxonomy and SAMR Model.

\subsection{Academic Performance}

Performance is defined by Tuckman as "the apparent demonstration of understanding concepts, skills, ideas and knowledge of a person and proposed that grades depict the performance of a student” (Tuckman, 1975). Hence, students' performance can be analyzed based on their skills and grades. Singer (1999) defined a performance test as the type of mental test in which the subject is asked to do something rather than to say something. The performance test is the type of test which throws light on the ability to deal with things rather than symbols (Drever, 1981). The current study also deals more with the ability to use social media in order to enhance learning rather than symbols while Muthee and Murungi (2018) offer the expression academic performance as to the percentage of marks obtained by the pupils on compulsory subjects. The present definition of performance is the performance of students which consists of skills and scores obtained from teacher-made activities and tests. Therefore, performance is referred as to scores obtained from tests conducted with students which will be taken after a topic or task that had been taught and completed.

\section{Problem Statement}

Studies have found that, regardless of continuous efforts to integrate new media into teaching and learning, the proportion of Malaysian students utilizing digital technologies during school and educational institutions remains moderately low (Ghavifekr, Kunjappan, Ramasamy, \& Anthony, 2016; Shariman, Razak, \& Noor, 2012; Sobaih, Moustafa, Ghandforoush, \& Khan, 2018). In the last 'Malaysian Blueprint 2015-2025', highlights the need to focus on rapid development innovations to deliver and adapt education for all students (Blueprint, 2015) as it recognizes that the education system will need to keep evolving to stay abreast with, if not ahead of, global trends. In the overall 10 shifts in the Malaysian Blueprint, the ninth shift focuses on all Malaysians participating in online learning and the need to use technology (Blueprint, 2015). According to the blueprint, blended learning models will become a staple pedagogical ap- 
proach in all Higher Learning Institutions (HLIs) in Malaysia. Besides, the ministry recognizes the changes that need to be done, including role modeling the ability to learn, relearn, and unlearn existing processes, skills, and behaviors (Blueprint, 2015).

In the present study, students need to prepare their Business Communication assignments using digital tools of the $21^{\text {st }}$ century to promote learning. Students' marks will affect if they are not computer illiterate as the tasks given are involved with the usage of technology. Technology is carefully woven into the fabric of the subject to illustrate the changing ways businesspeople are communicating and to introduce students to the tools they can be expected to encounter on the job. Robinson (2016) study had identified that there is a gap within the research through a comprehensive analysis with mixed results in technology integration. Harrell and Bynum (2018) highlighted that poor planning and organizing such as lack of digital tools, unskilled teachers, low motivational level of teachers, and teacher's overall confidence in the technology itself are some barriers towards technology integration. There is much research that had obtained negative results in technology integration (Alfelaij, 2016; Alhazmi \& Rahman, 2012; Robinson, 2016). Like any other model, the SAMR Model had been criticized and was highlighted as having weaknesses. Past researchers like Linderroth (2013), Aiyegbayo (2015), Hamilton, Rosenberg, and Akcaoglu (2016), Kihoza, Zlotnikova, Bada and Kalegele (2016), and Nkonki and Ntlabathi (2016) have all raised questions about the model's credibility and weaknesses at all the four stages of substitution, augmentation, modification and redefinition of the SAMR Model. The need to investigate the competency of the model as a pedagogical framework was felt needed. Based on this, the following research questions were raised.

1. Is there any significant difference in students' response towards a given task between the experimental and control groups in the substitution level of the SAMR Model?

2. Is there any significant difference in students' frequency of communication between the experimental and control groups in the augmentation level of the SAMR Model?

3. Is there any significant difference in students' performance between the experimental and control groups in the modification level of the SAMR Model?

4. Is there any significant difference in students' performance between the experimental and control groups in the redefinition level of the SAMR Model?

\section{Methodology}

This study was conducted during Spring 2019 for eight weeks. This is a quantitative study that was designed specifically to answer the question if there is a causal relationship between two variables with or without the integration of technology by using or not using a framework. In other words, whether changes in an independent variable cause change in a dependent variable. This design was found suitable as there would be two randomly assigned groups: an experimental group and a control group. The treatment will be applied to the experimental group and assessments were carried out on both groups to assess the effect of the treatment or manipulation. Homogeneity of variance was also conducted between both groups before starting the treatment to ensure the knowledge level between both groups are similar. The researcher had purposefully changed or manipulated the independent variable, which is the treatment or condition that was applied to the experimental groups which then had integrated technology for this study. It is important to establish clear procedural guidelines for the application of the treatment to promote consistency and ensure that the manipulation itself does affect the dependent variable. Participants should have an equal probability of being assigned to any group in the experiment (Creswell, 2012), therefore an assessment has been implemented prior to the intervention of treatment to both control and experimental groups to ensure the probability of equal knowledge. Both groups took a pre-test and post-test to compare student performance based on the topic learned which means there were two assessments, one in the beginning and another after the intervention. The first assessment determined the mean value between the experimental and control groups using the independent t-test. This method is used to minimize the threat of internal validity of the study and to ensure equal variance across samples or homogeneity of variance. This further ensures that the outcome of the study is due to the manipulation of the independent variable and is not influenced by the composition of the test groups. In addition to randomly assigning the test subjects in groups, it is also important to randomly select the test subjects from a larger target audience. After the intervention, another assessment was conducted between both groups to assess the effectiveness of technology integration, again using the independent t-test to compute data.

The samples in both the control and experimental groups are similar in numbers and characteristics, but the participants in the control group received no experimental treatment or any intervention. The experimental group received the planned treatment, and a comparison was made with the control group to observe the effect of this treatment. According 
to Price, Chiang, and Jhangiani (2015), an empirical study is said to be high in internal validity if the way it was conducted supports the conclusion that the independent variable causes any observed changes in the dependent variable. As a result, experiments are high in internal validity because of the way they are conducted — with the manipulation of the independent variable and the control of extraneous variables which provides strong support for causal conclusions.

The present study has higher internal validity to the extent that the way they are conducted supports the conclusion that the independent variable caused any observed differences in the dependent variable. The assessment tasks were conducted simultaneously on the same day and time. The essay assignments and presentations uploading dates were given on the same day. However, the roleplay for control groups was set in the afternoon with two markers as judges. The recorded roleplays/presentation was asked to be uploaded to YouTube on the same day, but the time was set up to 12 midnight. The manipulation of the independent variable and control of extraneous variables usually generates a higher internal validity (Price, Chiang, \& Jhangiani, 2015). However, the way that experiments are directed at times to a different kind of criticism like for example, the manipulation of both the independent variable and control extraneous variables means that experiments are often carried out under conditions that seem artificial (Bauman, McGraw, Bartels, \& Warren, 2014). This issue relates to external validity.

An experimental study is concluded high in external validity if the way it supports generalizing the results to people and situations beyond those actually studied. Although experiments can seem "artificial" —and low in external validity-its' psychological processes under study need to be considered and whether they are likely to operate in other people and situations (Price, Chiang, \& Jhangiani, 2015).

The current study has sixty samples. Each group has thirty students. There is a disproportionate number of participants when it comes to males and females. The samples are with the age range of 18 to 22 and Malaysian students. They have completed the Malaysian Certificate of Education ('Sijil Pelajaran Malaysia') with 5 credits and pass in Mathematics and have sat for the pre-requisite paper, English Composition II, in the college. Therefore, statistical validity would not be an issue.

In addition to the results of an experiment, another element that needs to be scrutinized in a study is the quality of the experiment's manipulations, or the construct validity (Price, Chiang, \& Jhangiani, 2015). In evaluating this design, Price, Chiang, and Jhangiani (2015) claimed that the construct validity must be high because the experiment's manipulations clearly speak to the research question; like that there is a crisis, a way for the participant to help, and increasing the number of other students involved in the discussion, providing a way to test diffusion.

The above four big validities - internal, external, construct, and statistical, are useful when discussing experiment design. However, researchers had prioritized and suggested that the chances of having high validity in all four areas at times would be impossible. Table 1 shows how the findings were achieved based on the research questions. The SAMR Model for technology integration guides educators on the different "levels" of technology integration into the activities and classroom instruction.

Table 1. Research Questions and Assessment Methods

\begin{tabular}{ll}
\hline Research Questions & Method of assessment \\
\hline $\begin{array}{l}\text { Is there any significant difference in students' } \\
\text { response towards a given task between the } \\
\text { experimental and non-experimental groups in the } \\
\text { substitution level of the SAMR Model? }\end{array}$ & $\begin{array}{l}\text { There are } 6 \text { groups in the control group and } 6 \text { groups in the } \\
\text { experimental group. The earliest meeting for each group in } \\
\text { control groups and first response on Facebook based on the } 6 \\
\text { groups from the experimental group are compared. }\end{array}$ \\
$\begin{array}{l}\text { Is there any significant difference in students' } \\
\text { frequency of communication between the } \\
\text { experimental and non-experimental groups in the } \\
\text { augmentation level of the SAMR Model? }\end{array}$ & $\begin{array}{l}\text { Frequency in communication between both groups } \\
\text { (Meetings and Facebook communication) }\end{array}$ \\
$\begin{array}{l}\text { Is there any significant difference in students' } \\
\text { performance between the experimental and non- } \\
\text { experimental groups in the modification level of } \\
\text { the SAMR Model? }\end{array}$ & $\begin{array}{l}\text { Essay Writing } \\
\begin{array}{l}\text { Is there any significant difference in students' } \\
\text { performance between the experimental and non- } \\
\text { experimental groups in the redefinition level of the } \\
\text { SAMR Model? }\end{array}\end{array}$ \\
\hline
\end{tabular}




\section{Findings and Discussions}

The data were collected during the Summer of 2019. The semester started on 13th May 2019 and ended on 3rd July 2019. There was a one-week study break, followed by a final examination. The study was conducted with two groups, control and experimental, with 60 business undergraduates in a private college in Melaka. The study for technology integration using the SAMR Model was conducted for eight weeks. There were 30 students for each group. In order to collect data for the research questions, experimental group students were invited to join a closed group on Facebook before intervention. Assessments, essay writings, and presentations were conducted and assessed for both groups, and data were computed thereafter. Results were computed using SPSS 20.The study analyzed student performance in terms of writing and presentation skill, assessment using technology.

\subsection{Research Question 1}

Results for the experiment were conducted to answer if there were any significant differences towards the first entry on Facebook by each group in the experimental group and the first meeting conducted by each group in the control group. Results showed that it did not have a big difference. The reason could be that students are meeting every day in their classes that they rather discuss face to face rather than communicating through Facebook. In this research question, one can conclude that Facebook is not a platform that students like to communicate continuously or since it is the short semester, they are busy with other subject assignments than to be active in Facebook. However, there is evidence that Facebook is a platform to share each-others' learning experience (Ainin, Naqshbandi, Moghavvemi, \& Jaafar, 2015) and students have not fully utilized the advantage it offers. To conclude, there is not much of a significant difference in students' submission towards a given task between the experimental and control groups in the substitution level of the SAMR Model. Therefore, at the substitution level, technology has not encouraged students to communicate in a quick manner as expected in the present study.

\subsection{Research Question 2}

The second research question investigates the frequency of communication between the control and experimental groups. Control groups are encouraged to conduct meetings to discuss the given assignments while experimental groups are encouraged to communicate through Facebook. Results identified that there is more active communication through Facebook than meeting when students are in the process of completing tasks. The result showed that the total meetings conducted between the six groups in control groups are 30 times while the experimental groups had 49 entries in Facebook (FB) between all six groups. Although the discussion group on FB was created for the students by the lecturer to promote interaction, it was found that most of the students were reluctant in participating and giving comments to their peers in the group. At the augmentation level, the students are expected to be in a deep learning level of understanding. It's crucial to provide individual knowledge areas of technology, pedagogy, and content however there is limited activity happening at the intersections of this knowledge. In the present study, students have actively participated in the Facebook discussion. Wu et al. (2012) reported from his study that the instant individual feedback is provided, it enables students to practice more compared to students using the traditional format. Similarly, discussion through Facebook enables students to actively participate and provide feedback. The conclusion that one can summarize is that with technology there is continuous communication between members of the groups compared to control groups who held meetings. There were limitations as they discuss only when they meet face to face which need to be arranged accordingly as all members need to attend discussions at the same time and place unlike students using technology, who can communicate at anytime or anyplace via Facebook.

\subsection{Research Question 3}

The third research question analyses the modification level. Scores from the essay writing task had been taken from both groups which were marked by two markers. The scores of the experimental group are higher than the control group. This shows that the integration of technology using the SAMR Model had provided a positive result in student performance in their essay writing.

Punya Mishra and Matthew Koehler (2006) stated that at the modification level of SAMR changes can be observed in this intersection as the knowledge gathered becomes important. Teachers will need support at TPACK areas of content, pedagogy, and technology, as different types of knowledge are needed to redesign tasks at this level.

"Facebook groups" is a feature that is available on social networking sites. The students in the current study had been placed with five members in each group in the experimental groups. The "Facebook group" feature allows members to participate, communicate and interact via post and chat-style for a specific purpose. They also can comment and like 
posts to show their support. For this study, a Facebook group was created specifically for the purpose of providing students with space where they were in control of the content and the direction of their learning, as well as providing more opportunities for students to brainstorm ideas to write. The teacher merely acts as a facilitator for the group. Facebook groups are also provided with immediate feedback and fun interaction that most probably improve their writing. Students share links and ideas from other sites which are shared with other members which enhance learning with technology. 'FB groups' provides a place where students' ideas are posted in viewed by all, it is also opened to criticism as well as praise. The higher-order thinking skills of Bloom's Taxonomy play a role in organizing, synthesizing, and analyzing ideas both by oneself and peers in constructing new knowledge (Yunus \& Salehi, 2012). This nurtures meaningful learning when the members of the group are able to brainstorm ideas that are shared and constructed through the response and feedback given by peers. A student develops confidence in writing through the fact that the ideas mentioned are supported and agreed upon by peers. The hypothesis for this research question is that Facebook groups have enhanced their skills in brainstorming ideas to improve their writing skills.

\subsection{Research Question 4}

The fourth research question analyses the redefinition level which is the highest level of the SAMR Model. At this stage, students worked in groups on creating videos with topics related to the subject matter. The students then coordinated their efforts and brainstormed ideas so that they produces and assembles a clip into an informative collection. The videos were then displayed on YouTube with additional resources for learning about the topic, and the site could include interactive elements, opening up a discussion forum where visitors ask questions and leave constructive feedbacks that would be curated and responded to by the students. The whole class had organized its efforts to make sure the quality of the final product. The videos and all other elements that students need to add in the clip will have an audience much larger than the class and a function that requires a much higher level of fluency and knowledge since the final uploading will be on YouTube. The given activity requires students to be creative and make organizational decisions to certify the clip is suitable for an audience beyond their school. What was once a simple in-college task has been transformed into a real-world learning tool for anyone with a web browser to see. This means that the clip will establish a much richer content level, with students not merely giving the information they found in their research but creating and delivering new information. They will have to function at the level of working in a group so that they can combine their efforts into one big task successfully. Finally, their clips will no longer be restricted to the general world of the classroom but will be released into either a controlled or an open environment. Feedbacks from the various audience will encourage knowledge sharing. Visualization in this context is any tool that can be used to take something that subtracts and make it concrete in two or three dimensions for students to look at and comprehend. The current research had identified that there is a positive outcome in student performance at this level.

\subsection{Discussions on Findings}

According to Puentedura (2012), in order to integrate technology at the Substitution level, lecturers need to develop some technology knowledge in order to decide how to substitute an activity into technology based. Facebook and meeting were analyzed in this level to measure student performance. Results showed there was not much of a significant on both groups in the substitution level of the SAMR Model. Lowerison, Sclater, Schmid, and Abrami, (2006) study claimed that students may interpret technology use in the classroom as being common. In addition, students may not consider technology as a tool that promotes learning anymore and might not manipulate it as it should to bring transformation for learning.

Wachira and Keengwe (2011) reported that teacher surveys completed by the National Centre for Education Statistics (2005) in technology integration barriers, showed constant declines in the use of technology integration to enhance student learning. This is found untrue as the students have actively used the social media platform to enhance learning in the current study. It goes along the line of Social Learning theory (Wood \& Bandura, 1989), which emphasizes the need to allow students to interact, communicate and collaborate. Past studies on technology integration have stated collaboration and sharing of resources as a successful method of enhancing student learning (Ahern, Feller, \& Nagle, 2016; Guo, Lee, \& Stevens, 2012; Kabilan, 2010). In addition, Eghdam, Hamidi, Bartfai, and Koch (2018) had highlighted that Facebook communication, like any other social media, is currently the most popular social media and has the potential to increase student participation. This is proved correct in the present study under augmentation level. Kihoza, Zlotnikova, Bada, and Kalegele, (2016), had proposed that the SAMR model be revised or augmented to become context-sensitive, as this level in the present study analyses students' frequency in commenting and participating rather than in a context. Therefore, the current modified framework is found suitable as it yielded a positive result.

Ping and Maniam (2015) investigated on the effectiveness of Facebook group discussion in writing performance us- 
ing Facebook in discussions. The study compared two groups of 15 matriculation students in Malaysia. Their studyidentified that brainstorming on Facebook had helped the group to organize their opinions before the actual writing task was conducted in class. The survey questionnaire found that the writing performance of the students showed improvement as they showed interest and read their peer's comments on Facebook. The ideas posted by their peers also have helped them to brainstorm ideas and thus found it easy to write the essay based on the given topic (Ping \& Maniam, 2015). Swayne (2017) study in the United States, which used the SAMR Model to integrate technology did not observe any relationship between technology integration levels and summative assessment. In contrast, the current study, however, had identified a positive relationship between technology integration and summative assessment. Students' essay writing skills had improved and provided a positive result in the modification level of the SAMR Model. Students were given the topic of diversity in the workplace. Students from control groups restricted their writing within their own country on how diversity can affect the workplace based on culture, language, communication, and technology. This is mainly because there is a limitation of materials and resources. However, the experimental group's essay writing went beyond their own country. Students in the experimental groups discuss based on a diverse workforce in Thailand, Britain, United States, Japan, Korea to name a few. Technology has made it possible for students to obtain information out from their own country and gather new information based on online browsing. Students were able to modify they answer by adding new information.

At the redefinition level, it increases the dimension of learning, generating significantly more opportunities for participation and learning within their community or outside of the community. In addition, at the redefinition level, it covers Bloom's taxonomy of evaluation and creation. Based on the presentation scores one can conclude that the scores of the experimental group are higher compared to the control group. These can be due to the difference in content and the lesser mistakes made in grammar and vocabulary. As the presentation clips are pre-recorded, errors can be minimized before uploading to an online platform. The current study shows that there is a significant difference in students' performance between the experimental and control groups in the redefinition level of the SAMR Model. The SAMR model had helped to ensure that when using technology, it develops students' 4C (critical thinking, creative thinking, communicating, and collaborating) skills and enhances their overall learning experience (Microsoft, 2018) in both essay writing and presentation. Technology allows a student to prepare their presentation attractively and with animation. One can bring together text, image, audio and video for storytelling to tell stories that can take the form of digital comics, digital videos, and interactivity. This can encourage students to create their own digital stories (Puentedura, 2012). The redefinition level had a positive result with students redefining the task and producing new knowledge and developing new skills. Similarly, for essay writing, the exposure towards technology had students obtaining relevant materials for the given task for their presentation assignment. Students were given the topic of diversity in the workplace. Students from control groups restricted their presentation clips within their own country on how diversity can affect the workplace. This is mainly because there is a limitation of materials and resources. However, the experimental group's clip went beyond their own country in the discussion.

Technology allows a student to obtain resources from all over the world unlike teaching with books and notes. There is a limitation of resources from books and students can only write from what they gather and from what they had read. Technology has greatly extended access to student education. We can link the present study with Education 3.0, which is very much involved in knowledge gained from collaboration and creation (Utomo, Bon, \& Hendayun, 2018). Flexible learning activities are encouraged, focusing on creativity, and social networking outside the usual boundaries of an institution. Learning is more on self-determination, self-oriented, self-driven, self-motivated and self-directed. The examination will be replaced with an authentic assessment where students will display relevant competencies. Project-based activity is given priority based on course-based. All these are possible with the intervention of technology in learning to gain knowledge.

Overall, the study had positive findings in student performance, except on the substitution stage of the SAMR model. At that level, there was no significant difference. The relationship of Bloom's taxonomy at all levels was positive. The same could be agreed for the TPACK except pedagogy and content were absent in the substitution level unlike the rest of the levels. In the SAMR Model, when activities are conducted Puentedura (2013), in the first two stages of substitution and augmentation, enhancement takes place. When activities are conducted in the modification and redefinition stages, transformation takes place.

Table 2 shows the relationship of the SAMR Model with the taxonomy of bloom, a model which is very much used in cognitive learning, and the TPACK. Applying this modified SAMR Model, students can design learning technology effectively. The table identifies that stage one of substitution, covers Bloom's taxonomy of remembering and understanding. As for TPACK, it only covers the technology and not content and pedagogy. The augmentation stage covers applying and analyzing elements of Bloom's taxonomy and also covers the pedagogy and content of TPACK. The 
modification and redefinition stage covers Bloom's Taxonomy of analyzing, evaluating, and creating. At this stage, students go through a transformation after doing activities to enhance their skills. Both the modification and redefinition stages cover the elements in TPACK which are pedagogy, content, and technology.

Therefore, the current study agrees with past researchers that the stage of substitution is still vague and does not have content and pedagogy to enhance learning (Aiyegbayo, 2015; Hamilton, Rosenberg, \&, Akcaoglu, 2016; Nkonki, \& Ntlabathi, 2016). Linderroth (2013) raised the issue of credibility of the SAMR Model highlighting that it is not new but actually is straightforward. The current study has given the credibility needed for the model. The comment of being straightforward is not acceptable as if the model is straightforward, there would not be so many confusions of the model with different interpretations from past researchers. Meanwhile, Hamilton and Rosenberg (2016) identified that there is an absence of context in substitution and augmentation stages. Kihoza, Zlotnikova, Bada, and Kalegele (2016) also felt that the augmentation stage should be revised to become context sensitive. The findings in the present study agrees with Rosenberg (2016) that there is the absent of content in the substitution stage, however, the augmentation level, has the presence of both content and pedagogy. This study has made the augmentation stage content sensitive as advised by Kihoza et al. (2016). Aiyegbayo (2015) commented that the redefinition stage produces no changes with teaching and learning and Nkonki and Ntlabathi (2016) had claimed that modification and redefinition stages lack in curriculum design and delivery. Referring to Table 2, the last two stages of the SAMR Model, modifying and redefinition have pedagogy and content presence in it. This revised SAMR Model is more stable, more credible, more user friendly for educators to ensure there is the present of pedagogy, content and technology in their curriculum. In future studies, we can change the activity in the substitution level with a different one to have the presence of content in it.

Table 2. The relationship of SAMR Model, Bloom's Taxonomy and TPACK

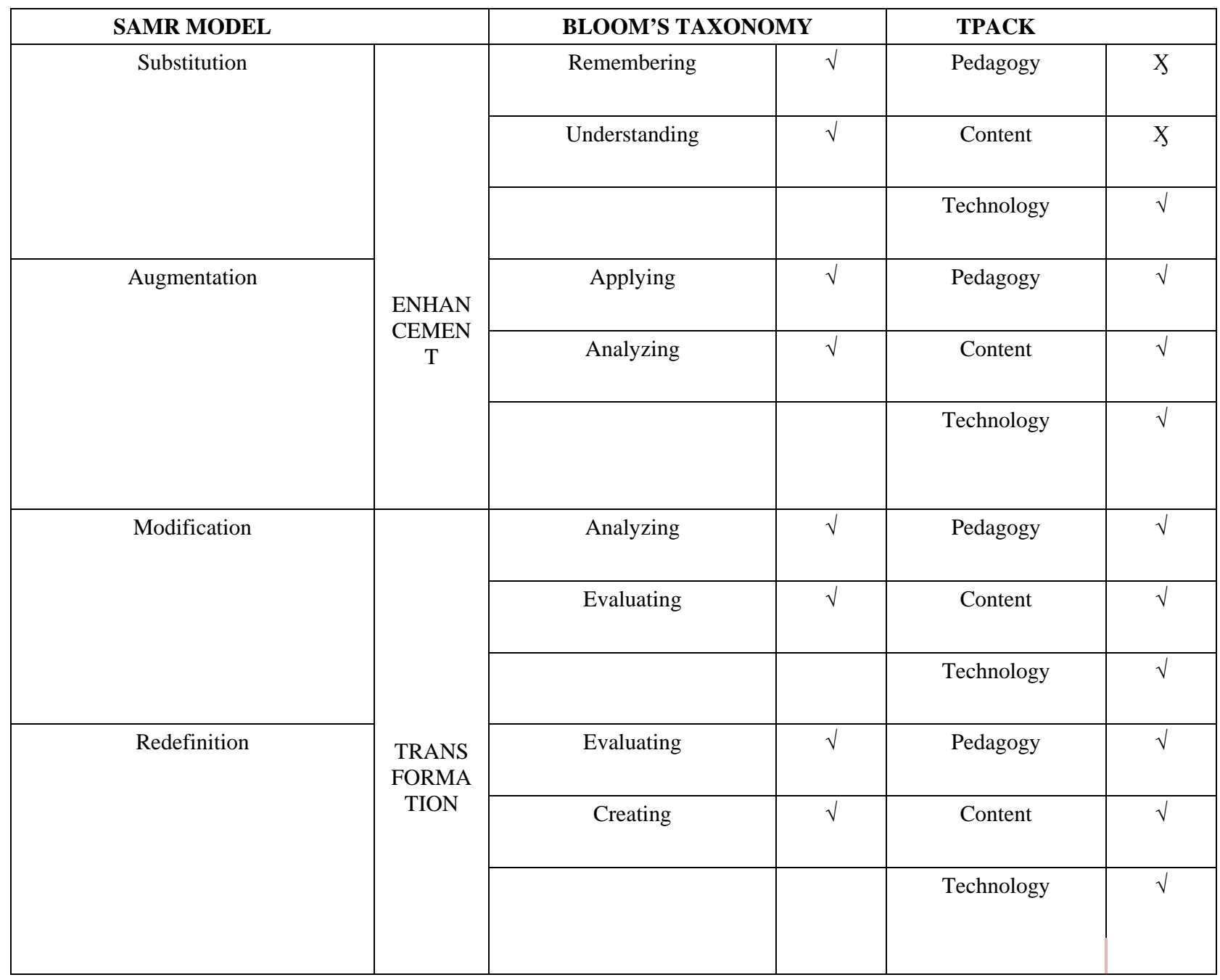




\section{Conclusion}

The new act required all Higher Education Providers (HEPs) to strictly follow the Malaysian Qualification Framework (MQF) which aligned the importance of the Outcome-Based Education (OBE) curriculum approach to all courses offered in private and public universities across Malaysia. Among one of the expectations were the shifts in higher education encouraging the massive use of educational technologies or digital skills (the ability to use information/digital technologies) for teaching and learning which was found a challenge and need much change (Blueprint, 2013).

Universities and colleges prepare their students for the future following the MQF and giving importance to OBE (Keating, 2013). There are potential prospective teachers among these students. Therefore, for the future of the world, innovative and productive teachers should be trained and very important for the lecturers of the education faculties of the universities and colleges to teach future teachers to give lessons using 21st-century curriculum and methods. Lecturers' tasks are evolving and are becoming "educators", "facilitators", "instructors", "coaches" and "e-moderators" rather than one-dimensional teachers. Therefore, lecturers should be aware of the challenges that they need to face when they choose a career in the education field.

Among the many teaching models that are being taught in teacher's training centers and the educational degrees, the SAMR Model should also be introduced. Teachers and lecturers should be taught the elements in the SAMR Model and possibly education institutions can invite scholars who are well versed in the SAMR Model to have a workshop. Educators should be flexible in choosing the model that they are comfortable with when integrating technology in classrooms. Even though one is introduced with all the available teaching models, but the question arises on how many teachers are using models when teaching. However, the SAMR Model should be analyzed further and remodify to cater to educators. Since the model itself can create confusion among those who are using it as each is giving its own interpretation of the model. The model should clearly define the role of Bloom's Taxonomy and TPACK so that teachers can use them without hesitation. The model should be user-friendly so that teachers can use it with ease. Ideas on how to prepare a lesson plan using the model should be made available. It was said that the author of the SAMR Model, did not provide much study using the model which makes it rather vague.

The SAMR model has potential uses in spite of its criticism. The critics of the model are correct that learning outcomes are the ultimate measurement; however, educators have many resources and academic theories to help create and evaluate curricula. The educational scene is changing, and technology is becoming part of the curricula and it is claimed that it is required to learn, as technological literacy is quickly becoming a required 21st-century skill (Hilton, 2016). The SAMR model is certainly reminiscent of a model that is first in the realm of cognitive education. Incorporating this model in teaching and learning will enhance the use of technology effectively.

\section{References}

Ahern, L., Feller, J., and Nagle, T. (2016). Social media as a support for learning in universities: an empirical study of Facebook Groups. Journal of Decision systems, 25(sup1), 35-49. https://doi.org/10.1080/12460125.2016.1187421.

Aiyegbayo, O. (2015). How and why academics do and do not use i P ads for academic teaching? British Journal of Educational Technology, 46(6), 13241332. https://doi.org/10.1111/bjet.12202.

Alfelaij, B. (2016). Why integrating technology has been unsuccessful in Kuwait? An exploratory study. E-Learning and Digital Media, 13(3-4), 126-139. https://doi.org/10.1177/2042753016672901.

Alhazmi, A. K. and Rahman, A. A. (2012, October). Why LMS failed to support student learning in higher education institutions. In E-Learning, E-Management and E-Services (IS3e), 2012 IEEE Symposium on (pp. 1-5). IEEE. http://dx.doi.org/10.1109/ IS3e.2012.6414943.

Aloraini, S. (2012). The impact of using multimedia on students' academic achievement in the College of Education at King Saud University. Journal of King Saud University-Languages and Translation, 24(2), 75-82. https://doi.org/10.1016/ j.jksult.2012.05.002.

Ainin, S., Naqshbandi, M. M., Moghavvemi, S., and Jaafar, N. I. (2015). Facebook usage, socialization and academic performance. Computers \& Education, 83, 64-73. https://doi.org/10.1016/j.compedu.2014.12.018.

Bauman, C. W., McGraw, A. P., Bartels, D. M., and Warren, C. (2014). Revisiting external validity: Concerns about trolley problems and other sacrificial dilemmas in moral psychology. Social and Personality Psychology Compass, 8(9), 536-554. https://doi.org/10.1111/spc3.12131.

Blueprint. (2015). M. E. Blueprint 2015-2025 (Higher Education) Executive Summary. Ministry of Education.

Blueprint, M. S. E. Blueprint 2015-2018. (2015). Malaysian Global Innovation \& Creativity (MaGIC, 2015), Unleashing the power 
of social entrepreneurship.

Creswell, J. W. (2012). Educational research. Planning, conducting, and evaluating quantitative and qualitative research. ISBN-13:9780131367395.

Cuban, L., Kirkpatrick, H., and Peck, C. (2001). High access and low use of technologies in high school classrooms: Explaining an apparent paradox. American Educational Research Journal, 38(4), 813-834. https://doi.org/10.3102/00028312038004813.

Drever, J. (1981). The penguin dictionary of psychology. Middlesex: Penguin Books Ltd.

Dudeney, G. (2010). The Internet and the language classroom. Ernst Klett.

Ghavifekr, S., Afshari, M., and Amla Salleh. (2012). Management strategies for E-Learning system as the core component of systemic change: A qualitative analysis. Life Science Journal, 9(3), 2190-2196.

Ghavifekr, S., Kunjappan, T., Ramasamy, L., and Anthony, A. (2016). Teaching and Learning with ICT Tools: Issues and Challenges from Teachers’ Perceptions. Malaysian Online Journal of Educational Technology, 4(2), 38-57.

Ghavifekr, S., and Rosdy, W. A. W. (2015). Teaching and learning with technology: Effectiveness of ICT integration in schools. International Journal of Research in Education and Science, 1(2), 175-191. DOI:10.21890/IJRES.23596.

Grabe, M. and Grabe, C. (2007). Integrating technology for meaningful learning (5th ed.). Boston, MA: Houghton Mifflin. DOI: 10.12691/jcsa-5-1-5.

Guo, Z., Li, Y., and Stevens, K. J. (2012). Analysing students’ technology use motivations: An interpretive structural modelling approach. Communications of the Association for Information Systems, 30, 199-224. DOI: 10.17705/1CAIS.03014.

Hamilton, E. R., Rosenberg, J. M., and Akcaoglu, M. (2016). The Substitution Augmentation Modification Redefinition (SAMR) Model: A Critical Review and Suggestions for its Use. TechTrends, 60(5), 433-441. DOI: 10.1007/s11528-016-0091-y.

Harrell, S. and Bynum, Y. (2018). Factors Affecting Technology Integration in the Classroom. Alabama Journal of Educational Leadership, 5, 12-18. Corpus ID: 150051118.

Hilton, J. T. (2016). A case study of the application of SAMR and TPACK for reflection on technology integration into two social studies classrooms. Social Studies, 107(2), 68-73. Doi: 10.1080/00377996.2015.1124376.

Hogan, L. (2010). The Maine Learning Technology Initiative: Professional development at the state, local school district, and classroom levels. Available at www.pearsonassessments.com/hai/images/NES_Publications/2010_09Hogan.pdf.

Hollebrands, K. (2020). How can Teachers Use Technology in the Classroom: Ask the Expert Series. https://ced.ncsu/news.

Kabilan, M., Ahmad, N., and Abidin, M. (2010). Facebook: An online environment for learning of English in institutions of higher education? The Internet and Higher Education, 13(4), 179-187. DOI: 10.1016/J.IHEDUC.2010.07.003.

Keating, J. (2011). The Malaysian qualifications framework. An institutional response to intrinsic weaknesses. Journal of Education and Work, 24(3-4), 393-407. https://doi.org/10.1080/13639080.2011.584699.

Kihoza, P., Zlotnikova, I., Bada, J., and Kalegele, K. (2016). Classroom ICT integration in Tanzania: Opportunities and challenges from the perspectives of TPACK and SAMR models. International Journal of Education and Development using Information and Communication Technology, 12(1), 107. Corpus ID: 102341234.

Kurt, S. (2018). “TPACK: Technological Pedagogical Content Knowledge Framework,” in Educational Technology, May $12,2018$. Retrieved from https://educationaltechnology.net/technological-pedagogical-content-knowledge-tpack-framework/.

Linderoth, J, (2013, October 17). Open letter to Dr. Ruben Puentedura [Blog post]. Retrieved from http://spelvetenskap.blogspot. com/2013/10/open-letter-to-dr-ruben-puentedura.htm.

Linderoth, J. (2013). Spelvetenskapliga betraktelser: Open letter to Dr. Ruben Puentedura. [online] Spelveten. skap.blogspot.ca. Available at: http://spelvetenskap.blogspot.ca/2013/10/open-letter-to-drruben-puentedura.html.

Lowerison, G., Sclater, J., Schmid, R. F., and Abrami, P. C. (2006). Student perceived effectiveness of computer technology us in post-secondary classrooms. Computer and Education, 47, 465-489. http://dx.doi.org/10.1016/j.compedu.2004.10.014.

Microsoft Asia News Center. (2018, May 23) Retrieved from: https://news.microsoft.com/apac/2018/05/23/meaningfultech-integration-for-better-learning-with-samr.

Muthee, J. M. and Murungi, C. G. (2018). Relationship Among Intelligence, Achievement Motivation, Type of School, and Academic Performance of Kenyan Urban Primary School Pupils. In Encyclopaedia of Information Science and Technology, Fourth Edition (pp. 1540-1547). DOI: 10.6007/IJARPED/v6-i4/3528.

Nkonki, V. and Ntlabathi, S. (2016, June). Teaching and Learning Innovations on Blackboard: What form and function? In ternational Conference on e-Learning (p. 120). Academic Conferences International Limited. Corpus ID: 34510683.

Ping, N. S. and Maniam, M. (2015). The Effectiveness of Facebook Group Discussions on Writing Performance: A Study in Matri- 
culation College. International Journal of Evaluation and Research in Education, 4(1), 30-37. DOI:10.11591/ijere.v4i1.4489.

Price, P. C., Chiang, I. C. A., and Jhangiani, R. (2015). Research methods in psychology. BCcampus, BC Open Textbook Project.

Puentedura, R. (2006). Transformation, Technology, and Education. Presentation given August 18, 2006 as part of the Strengthening Your District Through Technology workshops, Maine, US. Retrieved from http://hippasus.com/resources/tte/part1.html.

Puentedura, R. R. (2013). The SAMR model: Background and exemplars. Presentation slides. Retrieved on 28 March, 2015 from http://wiki.milaca.k12.mn.us/groups/samr/wiki/welcome/attachments/9dbda/ SAMR\%20Geography\%20Examples.pdf.

Robinson, K. (2016). The Effect of Technology Integration on High School Students' literacy Achievement. Teaching English with Technology, 16(3), 3-16. ISSN: EISSN-1642-1027.

Schlichter, A. (2020). The Impact of Covid-19 on Education: Insights from Education at a Glance. Paris: OECD Publishing.

Sobaih, A. E. E., Moustafa, M. A., Ghandforoush, P., and Khan, M. (2016). To use or not to use? Social media in higher education in developing countries. Computers in Human Behaviour, 58, 296-305. https://doi.org/10.1016/j.chb.2016.01.002.

S. Eghdam, A., Hamidi, U., Bartfai, A., and Koch, S. (2018). Facebook as communication support for persons with potential mild acquired cognitive impairment: A content and social network analysis study. PloS one, 13(1), e0191878. doi: 10.1371/journal.pone.0191878.2018.

Singer, J. (1999). Opinion gap: Measuring Public School Academic Performance ACS-VT 2000.

Shariman, T. P. N. T., Razak, N. A., and Noor, N. F. M. (2012). Digital literacy competence for academic needs: An analysis of Malaysian students in three universities. Procedia-Social and Behavioral Sciences, 69(1), 1489-1496. https://doi.org/10.1016/j.sbspro.2012.12.090.

Swayne, J. M. (2017). Staying Connected: Measuring the Impact of Technology Integration on Student Engagement and Achievement at the Middle Level.

Tuckman, H. P. (1975). Teacher effectiveness and student performance. The Journal of Economic Education, 7(1), 34-39.

Utomo, H. P., Bon, A. T., and Hendayun, M. (2018, July). The integrated academic nformation system support for education 3.0 in higher education institution: Lecturer perspective. In Journal of Physics: Conference Series (Vol. 1049, No. 1, p. 012102). IOP Publishing. DOI: 10.1088/1742-6596/1049/1/012102.

Yunus, M. M., Salehi, H., and Chenzi, C. (2012). Integrating social networking tools into ESL writing classroom: Strengths and weaknesses. English language teaching, 5(8), 42-48. DOI: 10.5539/elt.v5n8p42.

Wachira, P. and Keengwe, J. (2011). Technology integration barriers: Urban school mathematics teacher's perspectives. Journal of Science Education and Technology, 20(1), 17-25. DOI: 10.1007/s10956-010-9230-y.

Winter, E., Costello, A., O’Brien, M., and Hickey, G. (2021). Teachers' use of technology and the impact of Covid-19. Irish Educational Studies, 1-12. https://doi.org/10.1080/03323315.2021.1916559.

Wood, R. and Bandura, A. (1989). Social cognitive theory of organizational management. Academy of management Review, 14(3), 361-384. DOI: 10.5465/AMR.1989.4279067.

Wu, W. H., Wu, Y. C. J., Chen, C. Y., Kao, H. Y., Lin, C. H., and Huang, S. H. (2012). Review of trends from mobile learning studies: A meta-analysis. Computers \& Education, 59(2), 817-827. https://doi.org/10.1016/j.compedu.2012.03.016. 